\title{
Development and Validation of Stability- Indicating High-Performance Thin-Layer Chromatography Method for Estimation of Ciprofibrate in Bulk and in Pharmaceutical Formulation
}

\author{
P.S. JAIN*, H.N. JIVANI, R.N. KHATAL, AND S.J. SURANA \\ R.C. Patel Institute of Pharmaceutical Education and Research, \\ Karwand Naka, Shirpur Dist., \\ Dhule 425405 (M.S.), India \\ E-mail: pritash79@yahoo.com
}

\begin{abstract}
Summary. A simple, selective, precise, and stability-indicating high-performance thinlayer chromatography (HPTLC) method for the analysis of ciprofibrate both in bulk drug and pharmaceutical formulation has been developed and validated. The method employed HPTLC aluminum plates precoated with silica gel $60 \mathrm{RP}-18 \mathrm{~F}_{254}$ as the stationary phase. The solvent system consisted of methanol-water-triethylamine (2.8:2.2:0.2 $v / v)$. The system was found to give compact spot for ciprofibrate $\left(R_{\mathrm{F}}\right.$ value of $\left.0.55 \pm 0.02\right)$. Densitometric analysis of ciprofibrate was carried out in the absorbance mode at $232 \mathrm{~nm}$. The linear regression analysis data for the calibration plots showed good linear relationship with $r^{2}=0.998 \pm 0.0015$ with respect to peak area in the concentration range 600$1600 \mathrm{ng}$ per spot. The mean values \pm SD of slope and intercept were $3.38 \pm 1.47$ and $986.9 \pm 108.78$, respectively, with respect to peak area. The method was validated for precision, recovery, and robustness. The limits of detection and quantification were 17.84 and 54.08 ng per spot, respectively. Ciprofibrate was subjected to acid and alkali hydrolysis, oxidation, and thermal degradation. The drug undergoes degradation under acidic and basic conditions. This indicates that the drug is susceptible to acid and base. The degraded product was well resolved from the pure drug with significantly different $R_{\mathrm{F}}$ value. Statistical analysis proves that the method is repeatable, selective, and accurate for the estimation of investigated drug. The proposed developed HPTLC method can be applied for the identification and quantitative determination of ciprofibrate in bulk drug and pharmaceutical formulation.
\end{abstract}

Key Words: ciprofibrate, high-performance thin-layer chromatography (HPTLC), validation, stability, degradation

\section{Introduction}

Ciprofibrate, 2-[4-(2,2-dichlorocyclopropyl)phenoxy]-2-methylpropanoic acid (Fig. 1), is used to treat "hyper-lipidaemia", which is PPARa activators, have been documented to lower plasma triglycerides and cholesterol levels by decreasing elevated fibrinogen and PAI-1 levels and elevate the level of plasma HDL cholesterol [1-5]. Therefore, it is beneficial in the prevention of 
ischemic heart disease in individuals with elevated levels of LDL cholesterol.

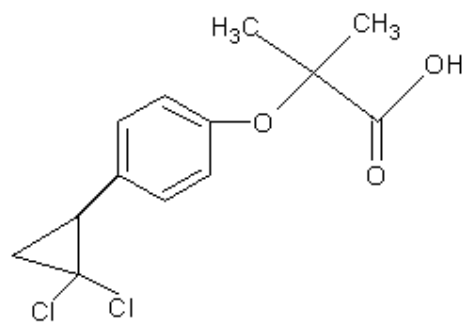

Fig. 1. Chemical structure of ciprofibrate

Various methods such as the determination of benzafibrate and ciprofibrate in pharmaceutical formulations by densitometry and videodensitometry thin-layer chromatography (TLC), the determination of benzafibrate, ciprofibrate and fenofibric acid in human plasma by highperformance liquid chromatography (HPLC), the enantiomeric resolution of ciprofibrate and related compounds by HPLC using chiral stationary phase, achiral and chiral determination of ciprofibrate and its glucuronide in human urine by capillary electrophoresis, HPLC, TLC densitometry and capillary electrophoresis are reported for the analysis of ciprofibrate in bulk and pharmaceutical formulation individually and in combination [6-9]. To our knowledge, no articles related to the stability-indicating chromatographic determination of ciprofibrate by high-performance thin-layer chromatography (HPTLC) in pharmaceutical dosage forms have been reported in literature. The International Conference on Harmonization (ICH) guidelines entitled "Stability Testing of New Drug Substances and Products" require the stress testing to be conducted to elucidate the inherent stability characteristics of the active substance. Susceptibility to oxidation is one of the required tests. Hydrolytic and photolytic stability are also required. An ideal stability-indicating method is one that quantifies the drug and also resolves its degradation products. Unlike HPLC, consumption of mobile phase per sample basis is quite low. This saves cost per analysis and analysis time as well. HPTLC facilitates repeated detection (scanning) of the chromatogram with the same or different parameters. HPTLC technique is most suited for impurity profile of drug substances and content uniformity test as per compendial specifications $[10,11]$. The aim of this work is to develop an accurate, specific, repeatable, and stability-indicating method for the determination of ciprofibrate in the presence of its degradation products as per ICH guidelines $[12,13]$. 


\section{Experimental}

\section{Chemicals and Reagents}

Ciprofibrate was supplied as a gift sample from Glenmark Pharmaceutical Ltd., Nashik, India. All chemicals and reagents used were of analytical grade and were purchased from Merck Chemicals, India.

\section{HPTLC Instrumentation}

The samples were spotted in the form of bands of $6 \mathrm{~mm}$ width with a Camag microlitre syringe on precoated silica gel aluminum plates 60 RP-18 $\mathrm{F}_{254}\left(10 \times 10 \mathrm{~cm}^{2}\right.$ with $250 \mathrm{~mm}$ thickness, E. Merck), using a Camag Linomat 5 applicator. The plates were prewashed with methanol and activated at $60^{\circ} \mathrm{C}$ for $5 \mathrm{~min}$ prior to chromatography. The slit dimension was kept at $6.00 \times 0.45 \mathrm{~mm}^{2}$ (micro), and $20 \mathrm{~mm} \mathrm{~s}^{-1}$ scanning speed was employed. The mobile phase consisted of methanol-water-triethylamine (TEA) (2.8:2.2:0.2, $v / v)$, and $10 \mathrm{~mL}$ of mobile phase was used. Linear ascending development was carried out in a $10 \times 10 \mathrm{~cm}^{2}$ twin trough glass chamber (Camag, Muttenz, Switzerland) saturated with the mobile phase. The optimized chamber saturation time for the mobile phase was $30 \mathrm{~min}$ at room temperature $\left(25 \pm 2^{\circ} \mathrm{C}\right)$. The length of the chromatogram run was $\sim 8 \mathrm{~cm}$. Subsequent to development, the TLC plates were dried in a current of air with the help of an air dryer. Densitometric scanning was performed on a Camag TLC scanner 3 and was operated by WinCATS software.

\section{Preparation of Standard Solution and Linearity Study}

An accurately weighed quantity of $10 \mathrm{mg}$ ciprofibrate was transferred to $10 \mathrm{~mL}$ volumetric flask and dissolved in methanol, and volume was made up to mark with the same solvent to obtain concentration of $1000 \mathrm{ng} \mu \mathrm{L}^{-1}$. Aliquots of standard solutions $0.6,0.8,1,1.2,1.4$, and $1.6 \mu \mathrm{L}$ of ciprofibrate were applied on TLC plates with the help of microlitre syringe, using Linomat 5 sample applicator to obtain the concentration of $600,800,1000$, 1200,1400 , and $1600 \mathrm{ng}$ per spot. The standard curves were evaluated for within-day and day-to-day reproducibility. Each experiment was repeated 6 times. 


\section{Method Validation}

\section{Precision}

Repeatability of sample application and measurement of peak area were carried out using six replicates of the same spot (1000 ng per spot of ciprofibrate). The intra- and inter-day variation for the determination of ciprofibrate was carried out at three different concentration levels of 1000, 1200, and 1400 ng per spot.

\section{Limit of Detection and Limit of Quantification}

In order to determine the detection and quantification limits, ciprofibrate concentrations in the lower part of the linear range of the calibration curve were used. Ciprofibrate solutions of 900, 1000, 1100, 1200, 1300, and $1400 \mathrm{ng}$ per spot were prepared and applied in triplicate. The limit of detection (LOD) and limit of quantification (LOQ) were calculated using equations $\mathrm{LOD}=3.3 \times N / B$ and $\mathrm{LOQ}=10 \times N / B$, where $N$ is the standard deviation of the peak areas of the drugs $(n=3)$, taken as a measure of noise, and $B$ is the slope of the corresponding calibration curve.

\section{Specificity}

The specificity of the method was ascertained by analyzing the standard drug and sample. The spot for ciprofibrate in sample was confirmed by comparing the $R_{\mathrm{F}}$ values and spectra of the spot with that of the standard. The peak purity of ciprofibrate was assessed by comparing the spectra at three different levels, i.e. peak start $(S)$, peak apex $(M)$ and peak end $(E)$ positions of the spot.

\section{Ruggedness}

Ruggedness of the method was performed by spotting $1000 \mathrm{ng}$ of ciprofibrate by two different analysts, keeping the same experimental and environmental conditions.

\section{Accuracy}

The analysed samples were spiked with extra $80 \%, 100 \%$, and $120 \%$ of the standard ciprofibrate, and the mixtures were analysed by the proposed method. At each level of the amount, six determinations were performed. 
This was done to check the recovery of the drug at different levels in the formulations.

\section{Robustness}

By introducing small changes in the mobile phase composition, the effects on the results were examined. Mobile phases having different compositions of methanol-water-TEA (2.5:2.5:0.2 and 3:2:0.2, v/v) were tried, and chromatograms were run. The amounts of mobile phase, temperature, and relative humidity were varied in the range of $\pm 5 \%$. The plates were prewashed by methanol and activated at $60 \pm 5^{\circ} \mathrm{C}$ for 2,5 , and $7 \mathrm{~min}$ prior to chromatography. Time from spotting to chromatography and from chromatography to scanning was varied from 0,20 , and $40 \mathrm{~min}$.

\section{Application of Proposed Method to Tablet Formulation}

To determine the concentration of ciprofibrate in tablets (labelled claim: $100 \mathrm{mg}$ per tablet), the contents of 20 tablets were weighed, their mean weight was determined, and they were finely powdered. The powder equivalent to $10 \mathrm{mg}$ of ciprofibrate was weighed. The drug from the powder was extracted with methanol. To ensure complete extraction of the drug, it was sonicated for $30 \mathrm{~min}$ and the volume was made up to $10 \mathrm{~mL}$. The resulting solution was filtered using $0.41 \mu \mathrm{m}$ filter (Millifilter, Milford, MA). The above solution (1000 ng per spot) was applied on TLC plate followed by development and scanning as described in the section "HPTLC Instrumentation". The analysis was repeated in triplicate.

\section{Forced Degradation of Ciprofibrate}

\section{Acid- and Base-Induced Degradation}

Ten milligrams of ciprofibrate were separately dissolved in $10 \mathrm{~mL}$ of methanolic solution of $0.1 \mathrm{M} \mathrm{HCl}$ and $0.1 \mathrm{M} \mathrm{NaOH}$. These solutions were kept for $8 \mathrm{~h}$ at room temperature in the dark in order to exclude the possible degradative effect of light. One millilitre from the above solutions was taken and neutralized and then diluted up to $10 \mathrm{~mL}$ with methanol. The resultant solutions were applied on TLC plate in triplicate $(10 \mu \mathrm{L}$ each, i.e. $1000 \mathrm{ng}$ per spot). The chromatograms were run as described in the section "HPTLC Instrumentation". 


\section{Hydrogen Peroxide-Induced Degradation}

Ten milligrams of ciprofibrate were separately dissolved in $10 \mathrm{~mL}$ of methanolic solution of hydrogen peroxide $(6.0 \%, v / v)$. The solution was kept for $8 \mathrm{~h}$ at room temperature in the dark in order to exclude the possible degradative effect of light. The resultant solution was applied on TLC plate in triplicate $(1 \mu \mathrm{L}$ each, i.e. $1000 \mathrm{ng}$ per spot). The chromatograms were run as described in the section "HPTLC Instrumentation".

\section{Photochemical Degradation}

The photochemical stability of the drug was also studied by exposing the stock solution to direct sunlight for $8 \mathrm{~h}$. The resultant solution $(1 \mu \mathrm{L}$, i.e. 1000 ng per spot) was applied on a TLC plate, and chromatograms were run as described in the section "HPTLC Instrumentation".

\section{Dry Heat Degradation Product}

The powdered drug stored at $55^{\circ} \mathrm{C}$ for $3 \mathrm{~h}$ under dry heat condition showed no significant degradation. In all degradation studies, the average peak areas of ciprofibrate after application (1000 ng per spot) of three replicates were obtained.

\section{Results and Discussion}

\section{Development of Optimum Mobile Phase}

TLC procedure was optimized with a view to developing a stabilityindicating assay method. Initially, methanol-water $(3: 2, v / v)$ gave good resolution with an $R_{\mathrm{F}}$ value of 0.55 for ciprofibrate, but typical peak nature was missing. Finally, the mobile phase consisting of methanol-water-TEA $(2.8: 2.2: 0.2, v / v)$ gave a sharp and well-defined peak at $R_{\mathrm{F}}$ value of 0.55 (Fig. 2). Well-defined spots were obtained when the chamber was saturated with the mobile phase for $30 \mathrm{~min}$ at room temperature. 


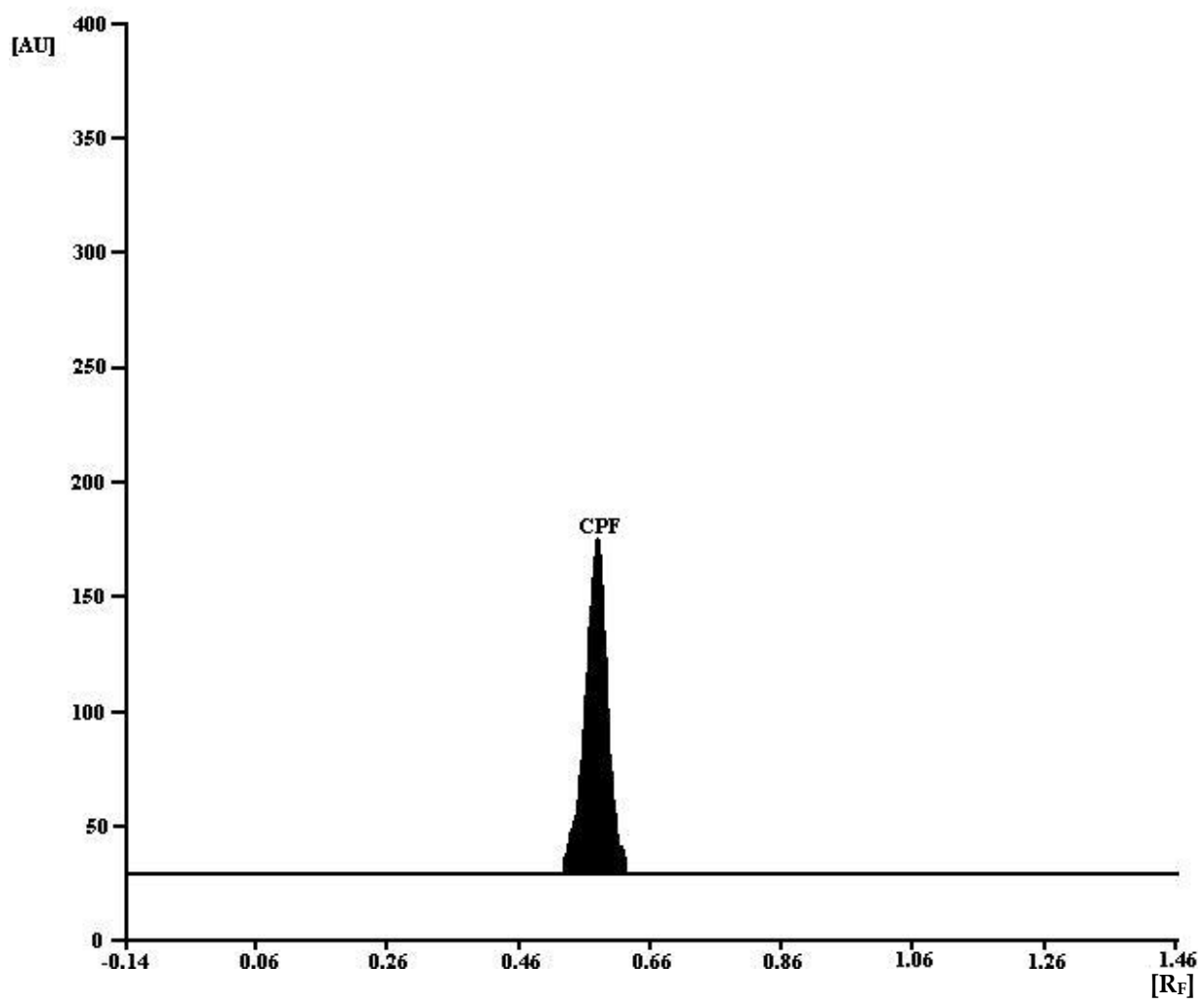

Fig. 2. Chromatogram of standard ciprofibrate $\left(R_{\mathrm{F}}: 0.55\right)$, UV detection at $232 \mathrm{~nm}$, mobile phase - methanol-water-triethylamine $(2.8: 2.2: 0.2 \mathrm{v} / \mathrm{v})$

\section{Calibration Curve}

The linear regression data for the calibration curves showed good linear relationship over the concentration range $600-1600 \mathrm{ng}$ per spot. Linear regression equation was found to be $Y=3.953 X+986.9\left(r^{2}=0.998\right)$.

\section{Validation of Method}

\section{Precision}

The precision of the developed HPTLC method was expressed in terms of percent relative standard deviation (\%RSD). The results, presented in Table I, revealed high precision of the method. 
Table I. Intra-day and inter-day precision of HPTLC method

\begin{tabular}{|c|c|c|c|c|c|}
\hline \multirow[b]{2}{*}{ Drugs } & \multirow{2}{*}{$\begin{array}{c}\text { Conc. } \\
\left(\text { ng } \mathrm{mL}^{-1}\right)\end{array}$} & \multicolumn{2}{|c|}{ Intra-day } & \multicolumn{2}{|c|}{ Inter-day } \\
\hline & & $\begin{array}{c}\text { Amount } \\
\text { found }(\%)^{a}\end{array}$ & $\%$ RSD & $\begin{array}{c}\text { Amount } \\
\text { found }(\%)^{a}\end{array}$ & $\%$ RSD \\
\hline \multirow{3}{*}{$\mathrm{CPF}$} & 1000 & 96.68 & 1.17 & 98.46 & 1.22 \\
\hline & 1200 & 103.94 & 0.84 & 101.23 & 0.72 \\
\hline & 1400 & 99.10 & 0.31 & 99.23 & 0.94 \\
\hline
\end{tabular}

aMean of three estimations

\section{LOD and LOQ}

Detection limit and quantification limit were calculated by the method described in the section "Limit of Detection and Limit of Quantification". The LOQ and LOD were found to be 54.08 and $17.84 \mathrm{ng}$, respectively. This indicates the adequate sensitivity of the method.

\section{Recovery Studies}

The proposed method when used for extraction and subsequent estimation of ciprofibrate from the pharmaceutical dosage formed after over spotting with $80 \%, 100 \%$, and $120 \%$ of additional drug afforded good recovery of ciprofibrate. The amounts of drug added and determined and the percentage recovery are listed in Table II.

Table II. Recovery study

\begin{tabular}{|l|c|c|c|c|}
\hline \multirow{2}{*}{ Drug } & $\begin{array}{c}\text { Label claim } \\
\text { (mg per tablet) }\end{array}$ & $\begin{array}{c}\text { Amount of } \\
\text { standard drug } \\
\text { added }(\%)^{\mathrm{a}}\end{array}$ & $\begin{array}{c}\text { Drug recov- } \\
\text { ered }\end{array}$ & \%RSD \\
\hline \multirow{3}{*}{$\mathrm{CPF}$} & \multirow{2}{*}{100} & 0 & 98.40 & 1.02 \\
\cline { 3 - 5 } & & 80 & 97.39 & 1.80 \\
\cline { 3 - 5 } & & 100 & 103.84 & 0.98 \\
\cline { 3 - 5 } & & 120 & 103.72 & 1.33 \\
\hline
\end{tabular}

aMean of three estimations at each level 


\section{Specificity}

The peak purity of ciprofibrate was assessed by comparing the spectra at peak start, peak apex, and peak end positions of the spot, i.e. $r^{2}(S$, $M)=0.9998$ and $r^{2}(M, E)=0.9988$. Good correlation $\left(r^{2}=0.9989\right)$ was also obtained between standard and sample spectra of ciprofibrate (Fig. 3).

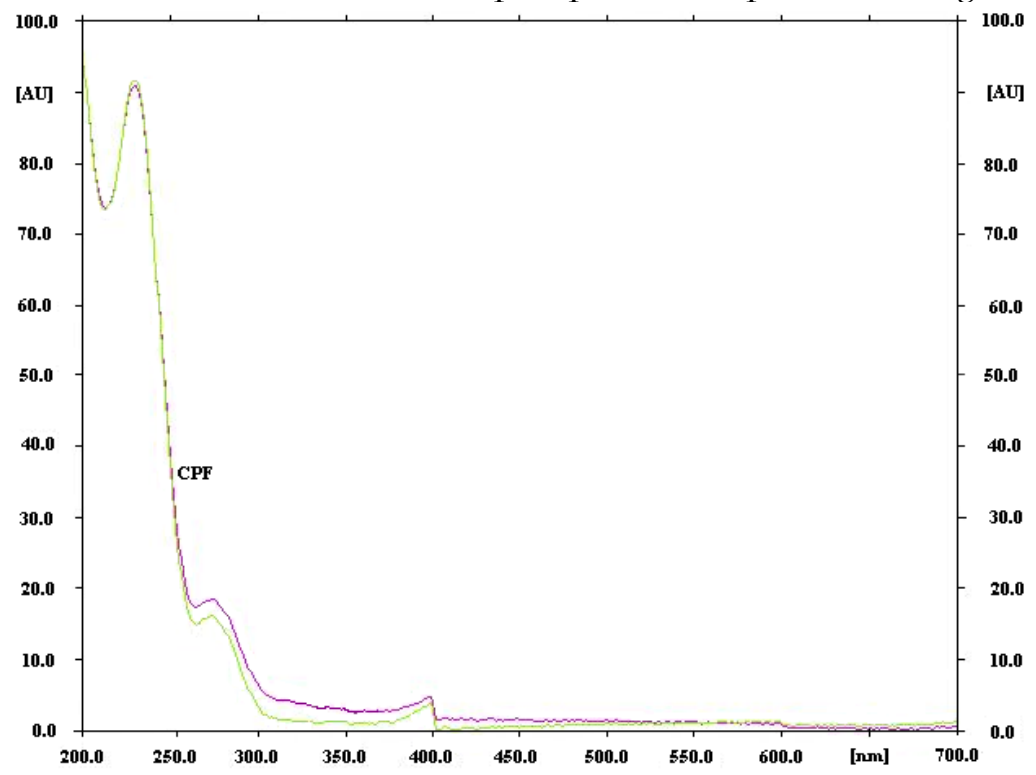

Fig. 3. Typical overlaid spectra of standard drug and drug extracted from tablet

\section{Robustness of the Method}

The standard deviation of peak areas was calculated for each parameter, and $\%$ RSD was found to be $<2 \%$. The low values of $\%$ RSD values, shown in Table III, indicated the robustness of the method.

Table III. Robustness of the method

\begin{tabular}{|l|c|c|}
\hline \multicolumn{1}{|c|}{ Parameter } & SD of peak area & \% RSD \\
\hline Mobile phase composition & 44.52 & 0.90 \\
\hline Mobile phase volume & 39.82 & 0.81 \\
\hline Development distance & 32.37 & 0.65 \\
\hline Activation of TLC plate & 39.84 & 0.81 \\
\hline Duration of saturation & 29.79 & 0.70 \\
\hline Time from spotting to chromatography & 21.16 & 0.50 \\
\hline Time from chromatography to scanning & 23.34 & 0.43 \\
\hline
\end{tabular}

$$
n=6
$$




\section{Analysis of the Marketed Formulation}

A single spot at $R_{\mathrm{F}} 0.55$ was observed in the chromatogram of the drug samples extracted from tablets. There was no interference from the excipients commonly present in the tablet. The \% drug content and \%RSD were calculated. The low \%RSD value indicated the suitability of this method for the routine analysis of ciprofibrate in pharmaceutical dosage forms (Table IV).

Table IV. Summary of validation parameters

\begin{tabular}{|l|c|}
\hline Parameter data & CPF \\
\hline Linearity range (ng per spot) & $600-1600$ \\
\hline Correlation coefficient & 0.998 \\
\hline Limit of detection (ng per spot) & 17.84 \\
\hline Limit of quantification (ng per spot) & 54.08 \\
\hline Recovery $(n=6)$ & 100.83 \\
\hline Ruggedness (\%RSD) & \\
\hline Analyst-I $(n=6)$ & 1.13 \\
\hline Analyst-II $(n=6)$ & 1.63 \\
\hline Precision $(\%$ RSD) & \\
\hline Repeatability of application $(n=6)$ & $0.96-1.29$ \\
\hline Inter-day $(n=6)$ & $0.56-1.50$ \\
\hline Intra-day $(n=6)$ & $0.21-1.62$ \\
\hline Robustness & Robust \\
\hline Specificity & Specific \\
\hline
\end{tabular}

\section{Forced Degradation}

The chromatogram of the acid-degraded samples for ciprofibrate showed additional peak at $R_{\mathrm{F}}$ value of 0.10 and 0.44 (Fig. 4), and base-degraded drug shows at $0.03,0.15$, and 0.17 (Fig. 5), respectively. The spot of the degraded product was well resolved from the ciprofibrate spot. In both cases, the concentration of the drug was changing from the initial concentration, indicating that ciprofibrate undergoes degradation under acidic and basic conditions. This indicates that the drug is susceptible to acid-base hydrolysis. The chromatograms of hydrogen peroxide, photo-degraded, and dry heat sam- 
ples of ciprofibrate showed only the spots of the pure drug (Figs 6-8). The lower $R_{\mathrm{F}}$ values of degraded components indicated that they were less polar than the analyte itself. The results are listed in Table $V$.

Table $V$. Degradation of ciprofibrate

\begin{tabular}{|c|c|c|c|c|c|}
\hline $\begin{array}{c}\text { S. } \\
\text { no. }\end{array}$ & $\begin{array}{c}\text { Sample exposure } \\
\text { condition }\end{array}$ & $\begin{array}{c}\text { Number of degra- } \\
\text { dation product }\end{array}$ & $\begin{array}{c}\text { Ciprofibrate } \\
\text { remained } \\
\text { (ng per } \\
1000 \mathrm{ng}) \\
( \pm \mathrm{SD}, n=3)\end{array}$ & SE & $\begin{array}{c}\text { Recovery } \\
(\%)\end{array}$ \\
\hline 1 & $0.1 \mathrm{~N} \mathrm{HCl}, 8 \mathrm{~h}, \mathrm{RT}$ & $2(0.10,0.44)$ & 638.53 & 2.45 & 12.96 \\
\hline 2 & $0.5 \mathrm{~N} \mathrm{NaOH}, 8 \mathrm{~h}, \mathrm{RT}$ & $3(0.03,0.15,0.17)$ & 4737.7 & 3.04 & 96.54 \\
\hline 3 & $10 \% \mathrm{H}_{2} \mathrm{O}_{2}, 8 \mathrm{~h}, \mathrm{RT}$ & 0 & 4893.3 & 1.76 & 99.71 \\
\hline 4 & $\mathrm{Heat}, 3 \mathrm{~h}, \mathrm{RT}$ & 0 & 4876.16 & 1.74 & 99.37 \\
\hline
\end{tabular}

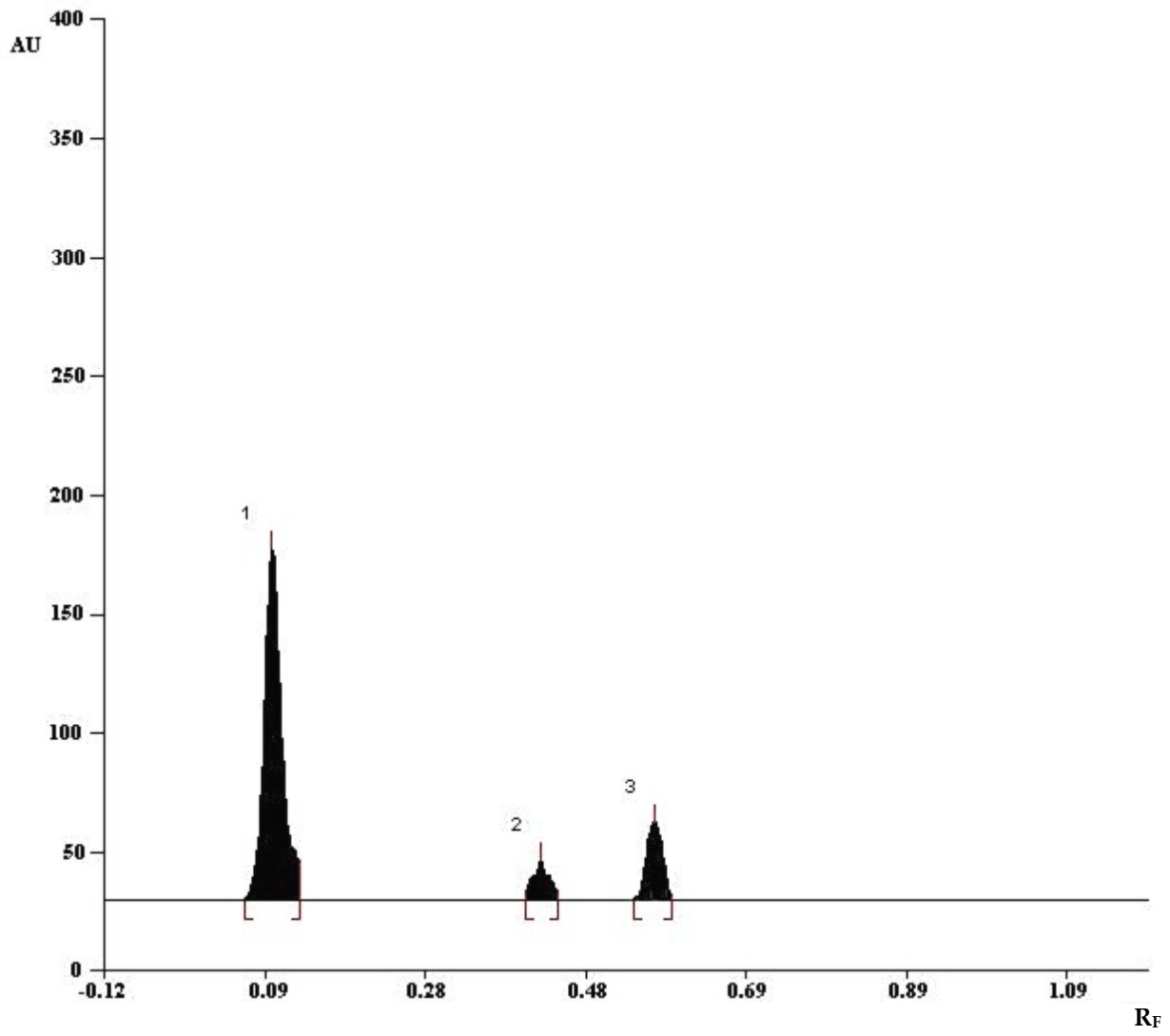

Fig. 4. HPTLC chromatogram of acid-treated $(0.1 \mathrm{~N} \mathrm{HCl}, 8 \mathrm{~h}, \mathrm{RT})$ ciprofibrate: peak 1 (impurity) ( $\left.R_{\mathrm{F}}: 0.10\right)$; peak 2 (impurity) $\left(R_{\mathrm{F}}: 0.44\right)$; peak 3 (ciprofibrate) $\left(R_{\mathrm{F}}: 0.55\right)$ 


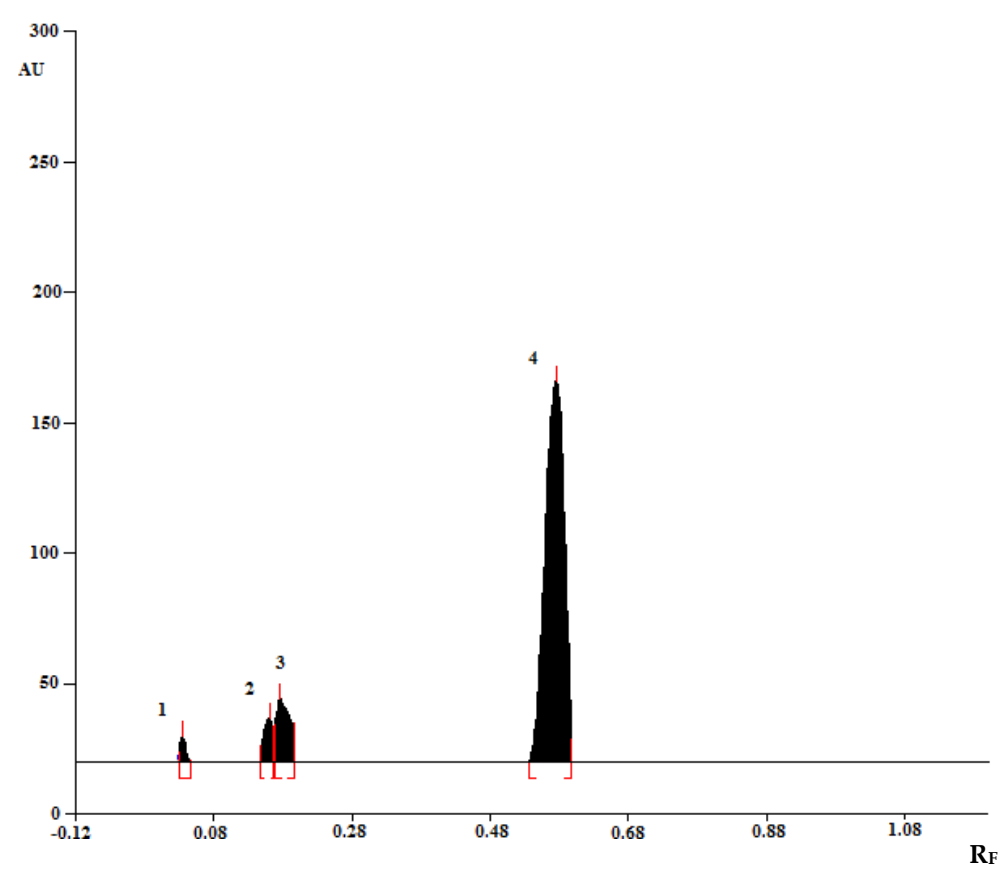

Fig. 5. HPTLC chromatogram of base-treated $(0.5 \mathrm{~N} \mathrm{NaOH}, 8 \mathrm{~h}, \mathrm{RT})$ ciprofibrate: peak 1 (impurity) $\left(R_{\mathrm{F}}: 0.03\right)$; peak 2 (impurity) $\left(R_{\mathrm{F}}: 0.15\right)$; peak 3 (ciprofibrate) $\left(R_{\mathrm{F}}: 0.17\right)$;

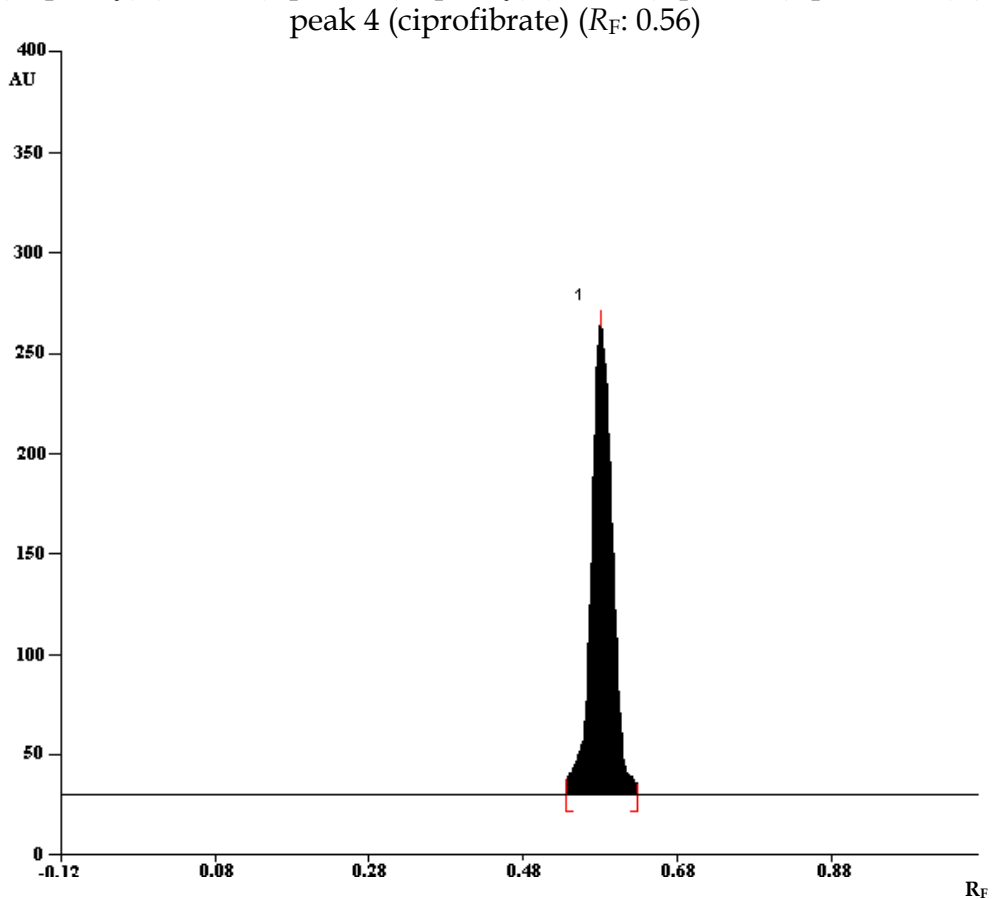

Fig. 6. HPTLC chromatogram of hydrogen peroxide-treated $(20 \% w / v, 8 \mathrm{~h}, \mathrm{RT})$ ciprofibrate: peak 1 (ciprofibrate) $\left(R_{\mathrm{F}}: 0.55\right)$ 


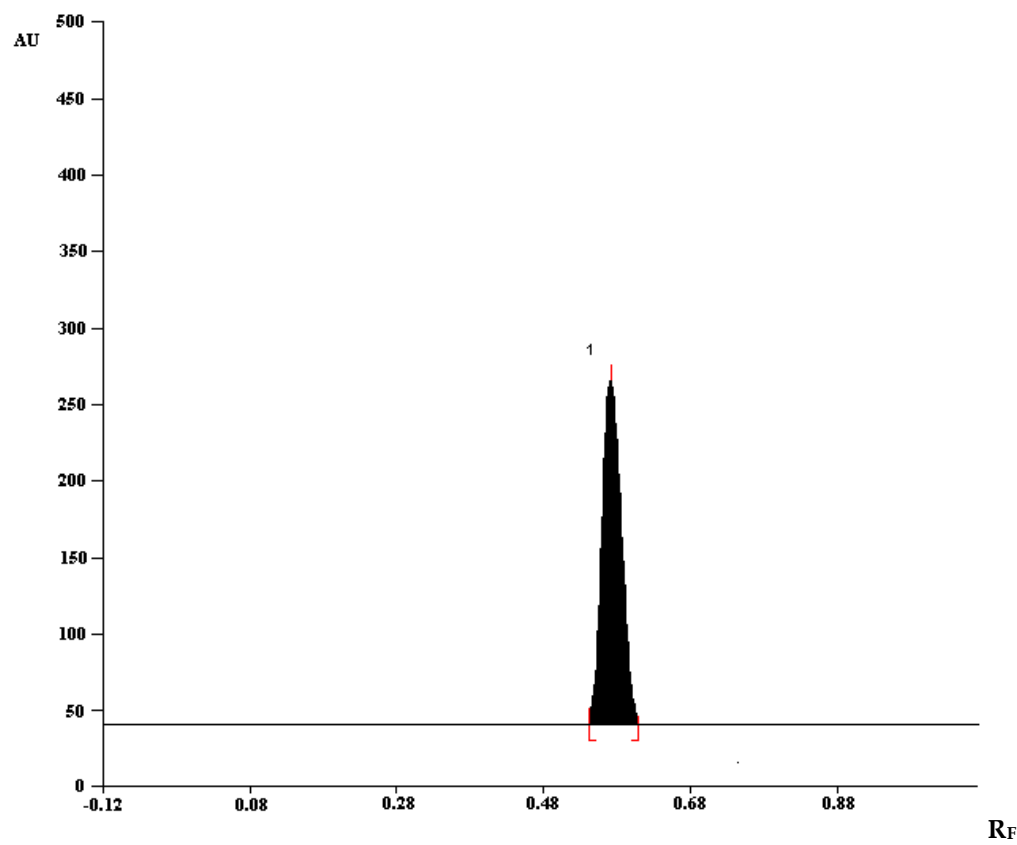

Fig. 7. HPTLC chromatogram of photo-degraded ( $24 \mathrm{~h})$ ciprofibrate: peak 1 (ciprofibrate) $\left(R_{\mathrm{F}}: 0.55\right)$

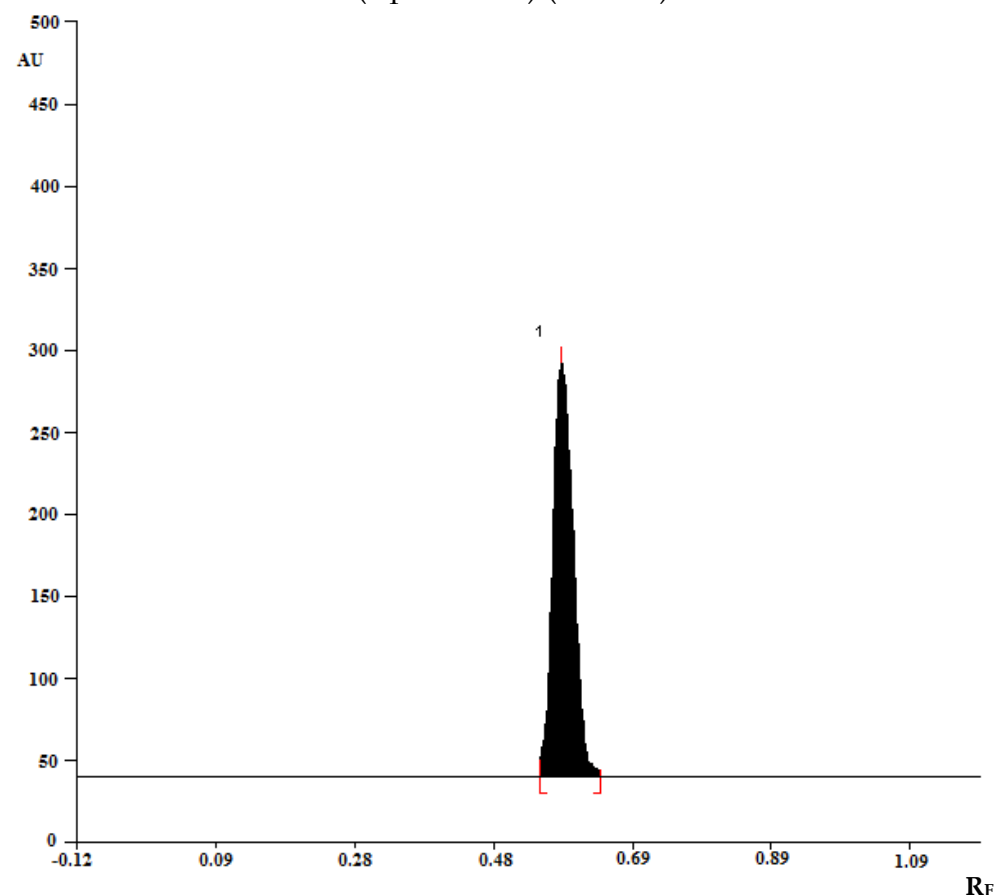

Fig. 8. HPTLC chromatogram of heat-treated $(8 \mathrm{~h}, \mathrm{RT})$ ciprofibrate: peak 1 (ciprofibrate) $\left(R_{\mathrm{F}}: 0.55\right)$ 


\section{Conclusion}

The developed HPTLC method was precise, specific, accurate, and stabilityindicating and validated based on ICH guidelines. Statistical analysis proves that the method is repeatable and selective for the analysis of ciprofibrate as bulk drug and in pharmaceutical formulations. The method can be used to determine the purity of the drug available from the various sources by detecting the related impurities. As the method separates the drug from its degradation products, it can be employed as a stabilityindicating one.

\section{References}

[1] Martindale: The Complete Drug Reference, 35th edn, Council of Royal Pharmaceutical Society of Great Britain, 2007, pp. 1118-1119

[2] S. Budavari, The Merck Index, 14th edn, Merck and Co., White House Station, New Jersey, 1996, p. 386

[3] Goodman and Gilman's: The Pharmacological Basis of Therapeutics, 10th edn, McGraw-Hill, New York, 2003-2004, pp. 971-1002

[4] British Pharmacopoeia, Medicinal and Pharmaceutical Substances (A-I), The Stationery Office, London, 2005, vol. 1, pp. 106-108

[5] E.G.B. Bighetti, P.R. Patricio, A.C. Casquero, J.A. Berti, and H.C.F. Oliveira, Lipids Health Dis., 50(8), 1-9 (2009)

[6] G. Misztal and L. Komsta, J. Planar Chromatogr., 18(3), 188-193 (2005)

[7] L.D. Masnatta, L. A. Cuniberti, R.H. Rey, and J. Werba, J. Chromatogr. B, 687(2), 437-442 (1996)

[8] N.H. Anderson, D. Johnston, and P.R. Vojvodic, J. Pharm. Biomed. Anal., 10(7), 501-505 (1992)

[9] H. Huttemann and G. Blaschke, J. Chromatogr. B, 729(1-2), 33-41 (1999)

[10] P.D. Sethi, High Performance Thin Layer Chromatography: Quantitative Analysis of Pharmaceutical Formulations, CBS, New Delhi, 1996, pp. 162-165

[11] M. Bakshi and S. Singh, J. Pharm. Biomed. Anal., 28, 1011-1040 (2002)

[12] ICH, Q2A text on validation of analytical procedures, International Conference on Harmonization, Geneva, October 1994

[13] ICH, Q3B validation of analytical procedures: methodology, International Conference on Harmonization, Geneva, November 1996

Accepted by DA 